\title{
Herding Breed
}

National Cancer Institute

\section{Source}

National Cancer Institute. Herding Breed. NCI Thesaurus. Code C53698.

The Herding Group members were formerly members of the Working Group. All breeds share the ability to control the movement of other animals. The vast majority of Herding dogs, as household pets, never cross paths with a farm animal. Nevertheless, pure instinct prompts many of these dogs to herd their owners, especially the children of the family. 